\title{
The Function of University Sports Organizations on the Construction of Campus Culture
}

\author{
Xiaojun Wang \\ Weinan Normal University, Physical College, Weinan, Shaanxi, 714000
}

Keywords: Campus culture construction; sports clubs; colleges and universities; quality and ability

\begin{abstract}
In recent years, with the reform of college education and the extensive development of quality education, the construction of campus culture is also constantly expanding. The community continually emerges. The colorful recreational activities have aroused the amateur cultural life on campus, Practical ability. College physical education is an important part of campus cultural life, but also the overall quality of college groups, cohesion, fighting spirit embodied. This paper studies the important role of college physical education in the construction of campus culture, analyzes the characteristics and current situation of university sports associations, and puts forward corresponding suggestions to improve the construction and development of sports associations.
\end{abstract}

\section{Introduction}

The purpose of college education is to cultivate all-round and comprehensive talents. Moral education is the direction, intellectual education is the main body, sports are the foundation, and the three promote and interact with each other. College culture is the overall reflection of higher education, but also the campus material and spiritual culture cluster, reflects the overall quality and cohesion of colleges and universities. College sports associations are an important part of the campus culture construction, and also an important measure to cultivate students' moral, intellectual and physical comprehensive development, adapt to the environment of reform and opening up, improve the quality of students and strengthen the school ideological and political construction.

\section{Campus Culture and University Sports Culture Overview}

Campus culture embodies the spirit and cohesion of colleges and universities, as well as a cluster of material and spiritual cultures on campus, which comprehensively reflects the quality of students' civilization and moral sentiment in the context of higher education. College culture is based on campus as a space, students as the main body, through the long-term education practice created by a campus atmosphere with a team characteristic, reflects the university's school spirit and style of study. Physical education is an integral part of university campus culture, including physical education, extracurricular activities, sports competitions and so on. The construction of college sports social community is a necessary measure to adapt to the reform environment and improve the overall quality of students.

The core of campus spirit is the campus culture, which embodies the cohesion and centripetal force of all the teachers and students in campus. It reflects the intrinsic value orientation and behavior of colleges and universities. Campus culture needs multi-level, three-dimensional and diversified. Healthy campus culture needs academic activities, also need sports activities, the two complement each other in order to enrich the campus culture and promote the development of campus culture. Sports culture is a catalyst for the development of campus culture, is to maintain the spiritual strength of the school community, is conducive to the construction of school atmosphere, promote spiritual civilization. Therefore, building a good campus culture and cultivating students 'awareness of lifelong physical education requires in-depth analysis of the relationship between college sports associations in the construction of campus culture, making full use of sports and cultural resources, promoting the development of university students' overall quality, building distinctive campus culture, People-oriented, improve the style and taste of campus 
culture.

\section{The role of college sports associations in the construction of campus sports culture}

College community is the carrier of campus culture, especially in recent years the education system reform, the full popularization of quality education, campus activities are also booming, sports associations to sports specialty characteristics as the basis, the establishment of basketball, soccer, volleyball, track and field, martial arts and other interests Group, covering a wide range of activities, frequent activities conducive to the shaping of students' knowledge and ability, overall quality improvement. According to the incomplete survey resources, more than $60 \%$ of students in colleges and universities participate in sports clubs and campus sports clubs are constantly expanding, and they are increasingly becoming effective carriers of quality education for college students, which plays an important role in improving college students' knowledge structure and professional skills. Here's a detailed analysis of the role of college sports associations in campus culture:

Sports activities are highly ideological and learning, is an indispensable spiritual force in the campus culture, its main purpose is to train people's value-oriented, inspiring, and nurturing, infected everyone in the campus. It plays an irreplaceable role in shaping ideas, cultivating souls, developing individuality and so on. Students participate in sports activities as well as other campus activities, and constantly improve themselves and effectively inhibit the negative social impact. As an important part of campus culture, college sports associations have a broad mass base and excellent moral education functions. To a certain extent, the sports associations in colleges and universities improve the pursuit of spiritual economy for campus students, they are full of love for beautiful things and maintain an optimistic mentality.

Young college students are the builders of the future of the motherland. Therefore, it is necessary to guide students to establish their ability to work hard and to train their talents. Only in this way can the cohesion of student groups be brought into full play. Athletic sports in sports activities require teamwork, which is an important activity of cohesion and unity, and can promote the all-round development of students to a certain extent. For example, at a university student sports meeting, athletes selected sports athletes to participate in the school games, and won the group in the school first. Counselors conduct educational discussions on team cooperation in real time to enhance collective cohesion and facilitate the smooth development of various work. An old professor who has been engaged in moral education for many years gave a high degree of recognition to the college games. He said: "The ideological and moral education in a school sports league is better than ten theme classes." Afterwards, after a great deal of practice, college physical education as an important part of campus culture has solidified the spiritual foundation and set up correct guidelines and a good learning environment for campus students. This atmosphere can arouse the students' recognition of the school and sense of mission, the formation of cohesion, the ultimate integration of the school's overall goal.

The work of campus culture should be positive, strengthen the motivation of students on campus, and arouse the enthusiasm and creativity of students. Physical activity has a high emotional, inspiring spiritual power. Campus culture is the core of school construction, and left the sports activities, the campus culture lost its due vitality and activities. After sports and sports activities through time and discipline constraints, and then follow the technical requirements of action, subject to a series of rules and other provisions of the referee, the timely completion of training and competition. Students also understand from the activity that in order to achieve their goals, they must follow the law and make continuous efforts and hard work. This is an important guarantee for college students to learn and become successful. Therefore, while carrying out knowledge education, we must cooperate with effective sports activities to inspire our students' collective sense of honor and to revitalize the campus culture.

With the reform of education and the popularization of quality education, society has higher requirements for the overall quality of college students. It not only needs to improve the education level and the quality of students, but also has new requirements for the spiritual culture. Therefore, 
in the construction of campus culture, we must increase investment in sports activities to meet the needs of students daily exercise. According to the survey found that students in the sports field is more likely to pass on their true feelings, respect the athletes, easy acquaintance of new friends. During the exercise, students in the campus can easily grasp moderate tolerance, how to cooperate and respect others, and help students to establish the correct concept and the three concepts of science.

\section{The status quo and existing problems of sports clubs in colleges and universities}

College student societies are usually managed by the school league in a unified manner and are responsible for managing the management of community documents and daily work. First, the internal division of labor within the association is not clear and management is chaotic. There is no real enforcement of the rules and regulations. In addition, the school league committee has its own thing, there is no full-time staff management. Second, the instability of the organization and the high mobility of its members; especially in higher vocational colleges, students have low cultural qualities, weak organizational concepts, three-point attendance, lack of patience and perseverance. Coupled with the activities of the community lack of planning and thoughtful thinking, it is difficult to stimulate interest in students, eventually leading to the end of the deserted. Thirdly, there is an unbalanced development of associations. There is an unbalanced development of sports associations, and there is a clear gap between athletic and performing performances. Diversified associations increase the choices of students and at the same time exacerbate the unbalanced development of associations. To a certain extent, Restricting the diversity of societies. Fourthly, there are not enough venues and insufficient funds. There is no fixed venues for sports associations in colleges and universities. Generally speaking, they are looking for suitable vacant venues during their spare time, which seriously hinders the development of sports associations. Activities mainly rely on members to pay membership dues to support, most of the institutions are not allocated, resulting in lack of funding for activities, difficult to meet the daily expenses of social activities. Fifth, the lack of professional guidance; physical education professionals already lack the appropriate faculty, coupled with physical education teachers had more jobs, it is difficult to serve as guidance for the community. In addition, community guidance is voluntary work, which has a serious blow to the enthusiasm of teachers. This makes the society lack professional guidance and systematic training.

\section{Strengthen the role of college physical education in the construction of campus culture}

Establishing and perfecting the operation mechanism of university sports in campus culture construction, integrating college physical education into campus culture, establishing the construction system based on the administrative implementation of the leadership of the party committee to manage it hierarchically, guiding by professional teachers to make detailed Activities in order to play the role of college physical education in the construction of campus culture, renewal of campus culture vitality and vitality. Strengthen college sports to guide the construction of campus culture, promptly promote sports culture, enrich the activities of sports associations and attract more students so as to enhance the vitality of the campus and enhance the cultural quality of college students.

Cultivating students' exercise habits and using sports as their own lifetime habit will require building a good campus sports culture, raising students' interest in sports, making positive comments on students' exercise behaviors, and using various means to reinforce them. Sports organizations in colleges and universities should also diversify the activities of organizations, combined with the development of the times, to carry out sports and cultural festivals. Diversified sports activities can enhance students 'initiative, integrate arts and culture into the competition, organically integrate sports activities with arts and culture, embody the connotation of humanities, enrich the content of activities, enhance the attractiveness of sports to students, and promote the students' The overall quality improvement.

The school conditions and types of school are not the same, the construction of campus culture 
from the training objectives of colleges and universities, traditional culture, combined with the characteristics of the curriculum and the characteristics of students, as far as possible the use of cooperative and proactive sports activities, increase reform efforts to promote The standardization and standardization of sports work have promoted the construction of campus culture. On the other hand, the school culture resources are limited, which requires colleges and relevant departments to jointly create activities to make up for lack of school cultural resources, promote community building, based on the university's own cultural traditions as the foundation, enrich sports and cultural activities, Optimize the cultural environment and improve the level of campus culture to achieve the role of college sports associations in the construction of campus culture.

Social activities can not be separated from the knowledge of the venue and funds, colleges and universities should be included in the allocation of funds and activities of student community activities to the school's overall planning to go through the project project reporting methods, the daily activities of student societies to give some funding and venue support to enhance student initiative. In addition, the social guidance teachers as a part of the workload, to mobilize the enthusiasm of teachers.

\section{Conclusion}

In summary, college sports associations can enhance the vigor and vitality of the campus and promote the healthy development of campus culture, to a certain extent, enhance the overall quality of students and practical ability, improve teaching efficiency. Although the sports associations in colleges and universities have encountered some difficulties during their development, educators are also actively exploring ways to find out corresponding countermeasures in time to solve the above problems and to improve the role of sports associations in the construction of campus culture.

\section{References}

[1] Chen Huadong, Banknote Xia, Lu Guangping university campus sports community in college sports status and role [J] higher agricultural education 2003,2 (2): 85-86

[2] Sun Ling-Yun On the Role of Students' Associations in the Construction of Campus Culture in Colleges and Universities of Physical Education [J] Journal of Nanjing Institute of Physical Education2004 (2)

[3] Liao Ying moral education colleges and universities under the perspective of cultural construction approach [J] Higher Education Research 2010 (1) 